\title{
Effect of the Direct Renin Inhibitor Aliskiren on Urinary Albumin Excretion in Spontaneous Type 2 Diabetic KK- $A^{y}$ Mouse
}

\author{
Masako Furukawa, Tomohito Gohda, Shinji Hagiwara, Mitsuo Tanimoto, \\ Satoshi Horikoshi, Kazuhiko Funabiki, and Yasuhiko Tomino \\ Division of Nephrology, Department of Internal Medicine, Juntendo University Faculty of Medicine, 2-1-1 Hongo, Bunkyo-ku, \\ Tokyo 113-8421, Japan \\ Correspondence should be addressed to Yasuhiko Tomino; yasu@juntendo.ac.jp
}

Received 15 March 2013; Accepted 8 May 2013

Academic Editor: Alejandro Martín-Malo

Copyright (C) 2013 Masako Furukawa et al. This is an open access article distributed under the Creative Commons Attribution License, which permits unrestricted use, distribution, and reproduction in any medium, provided the original work is properly cited.

\begin{abstract}
Objective. Although angiotensin II-mediated inflammation and extracellular matrix accumulation are considered to be associated with the progression of diabetic nephropathy, these processes have not yet been sufficiently clarified. The objective of this study was to determine whether the correction of the abnormal renal expression of MMPs and its inhibitors (MMPs/TIMPs) and cytokines following the administration of aliskiren to KK- $A^{y}$ mice results in a renoprotective effect. Methods. KK- $A^{y}$ mice were divided into two groups, that is, untreated (saline) and treated (aliskiren) groups. Systolic BP, HbAlc levels, and the albumincreatinine ratio (ACR) were measured. The renal expression of MMPs/TIMPs, fibronectin, type IV collagen, MCP-1, and (pro)renin receptor ((P)RR) was examined using real-time PCR and/or immunohistochemical staining. Renal MAPK and NF- $\kappa \mathrm{B}$ activity were also examined by Western blot analyses and ELISA, respectively. Results. Significant decreases in systolic BP and ACR levels were observed in treated KK- $A^{y}$ mice compared with the findings in untreated KK- $A^{y}$ mice. Furthermore, increases in MMPs/TIMPs, fibronectin, type IV collagen, MCP-1, and (P)RR expression, in addition to MAPK and NF- $\kappa \mathrm{B}$ activity, were significantly attenuated by aliskiren administration. Conclusions. It appears that aliskiren improves albuminuria and renal fibrosis by regulating inflammation and the alteration of collagen synthesis and degradation.
\end{abstract}

\section{Introduction}

Recent studies suggest that chronic inflammation and extracellular matrix (ECM) accumulation promote the progression of diabetic nephropathy (DN) $[1,2]$. We have also reported the increased renal expression of monocyte chemotactic protein (MCP)-1, fibronectin, and type IV collagen in KK- $A^{y}$ mice [3-5], a frequently used animal model of type 2 diabetes (T2D) [6]. Furthermore, angiotensin (Ang) II induces the phosphorylation of mitogen-activated protein kinase (MAPK) and increases nuclear factor (NF) $-\kappa B$ binding activity in this mouse model [5]. Several studies have suggested that the renin-angiotensin system (RAS) is one of the major mediators of the progression of glomerular hypertension, inflammation, and tubulointerstitial fibrosis, which leads to the progression of DN [7-9].
Aliskiren is the first agent in a new class of orally effective direct renin inhibitors approved for hypertension treatment $[10,11]$. In contrast to conventional RAS blockers, angiotensin-converting enzyme (ACE) inhibitors and Ang II type 1 receptor blockers (ARBs), aliskiren blocks RAS by directly inhibiting plasma renin activity and preventing the formation of both Ang I and Ang II, as demonstrated by basic and clinical findings $[10,12]$. Data from the AVOID trial suggest that the addition of aliskiren to an ARB provides an additive antiproteinuric effect compared to that of the ARB alone [13]. From the ALTITUDE study [14], the potential cardiorenal benefit and safety of aliskiren in a broad range of high-risk patients with T2D remain controversial. Further basic studies will be required to understand the mechanism of action of aliskiren in the prevention of renal disease progression. 
A strong correlation exists between interstitial expansion and glomerulosclerosis via alterations in renal blood flow, altered hemodynamics, and the direct effect of glucose; all of which promote the accumulation of ECM and the activation of profibrogenic and inflammatory cytokines [15]. Imbalances between the synthesis and degradation of glomerular ECM proteins by MMPs and its inhibitors (MMPs/TIMPs) are believed to play important roles in the progression of glomerular sclerosis in DN because high glucose or Ang II may induce alterations in the MMPs/TIMPs balance [16]. There is a positive crosstalk between inflammation and ECM synthesis that ultimately leads to chronic renal failure [17]. However, the role of MMPs/TIMPs within the context of diabetes remains controversial.

In the present study, we hypothesized that the direct renin inhibitor aliskiren may improve early $\mathrm{DN}$ via the attenuation of inflammatory cytokine expression and/or modulation of alteration MMPs/TIMPs expression in the kidneys of KK- $A^{y}$ mice.

\section{Methods}

2.1. Experimental Animals and Protocols. Six-week-old male $\mathrm{KK} / \mathrm{Ta} \mathrm{Jcl}$ and diabetic KK- $A^{y} / \mathrm{Ta} \mathrm{Jcl}$ mice were purchased from CLEA Japan (Tokyo, Japan). The mice were individually housed in plastic cages with free access to food (rodent pellet diet NMF; $348 \mathrm{kcal} / 100 \mathrm{~g}$, containing 5.5\% crude fat) and water throughout the experiments. All mice were maintained in the same room under conventional conditions with a regular 12-h light/dark cycle and temperature controlled at $24 \pm 1^{\circ} \mathrm{C}$. All experiments were performed according to the guidelines of the Animal Care Committee of Juntendo University. Aliskiren was kindly given by Novartis Pharma AG (Basel, Switzerland). KK- $A^{y}$ mice were divided into two groups: (1) vehicle group (nontreatment) and (2) aliskiren ( $25 \mathrm{mg} / \mathrm{kg}$ per day) group ( $n=10$ or 11 per group). Aliskiren was subcutaneously infused via an ALZET micro-osmotic pump (Durect Co., Cupertino, CA, USA). Drug treatment was performed for 4 weeks (from 8 to 12 weeks of age). The drug doses were determined from the previous studies [18]. ALZET micro-osmotic pumps loaded with saline were used in the nontreatment KK- $A^{y}$ and KK mice groups. Agematched untreated KK mice with nearly normal glucose tolerance levels were used as a control for the KK- $A^{y}$ mice. The experimental procedure was terminated when the mice reached 12 weeks of age. The mice groups were as follows: 8 weeks untreated KK mice group (Group1), 12 weeks untreated KK mice group (Group2), 8 weeks untreated $\mathrm{KK}-A^{y}$ mice group (Group3), and 12 weeks untreated $\mathrm{KK}-A^{y}$ mice group (Group4), and 12 weeks treated KK- $A^{y}$ mice group (Group5).

2.2. Biochemical Measurements. Body weight (BW), systolic blood pressure (SBP), fasting blood glucose (FBG) levels, hemoglobin Alc (HbAlc) levels, and the urinary albumincreatinine ratio (ACR) were measured at 8 or 12 weeks of age. Urinary samples were collected for $24 \mathrm{~h}$ using a metabolic cage (mouse metabolic cage, CLEA Japan). Urinary albumin and creatinine levels were measured by immunoassays (DCA
2000 System; Bayer Diagnostics, Elkhart, IN). Glucose levels of blood obtained from the retro-orbital sinus were measured using a Glucocard meter (Kyoto Daiichi Kagaku, Kyoto, Japan). HbA1c levels were also measured by an immunoassay (DCA 2000 system). Blood pressure was measured by a pulse transducer system (Softron BP-98A, Tokyo, Japan). Standard deviations (SDs) of less than 5.0 were used to define the levels of blood pressure, as described previously $[4,19]$.

2.3. Real-Time PCR for MMP-2, MMP-9, TIMP-1, TIMP2, Fibronectin, Type IV Collagen, MCP-1, and (Pro) Renin Receptor Expression. RNA was extracted from snap-frozen renal cortices using the RNeasy Mini Kit (Qiagen KK, Tokyo, Japan). RNA was reverse-transcribed using random decamer primers (Ambion, Austin, TX, USA) and MMLV Reverse Transcriptase (Life Technologies, Carlsbad, CA, USA). TaqMan real-time PCR was performed and analyzed according to the manufacturer's instructions (Applied Biosystems, Foster City, CA, USA). To measure gene expression in each tissue fraction, real-time PCR was performed using primers supplied with the commercially available assays obtained from Applied Biosystems (MMP-2: Mm01253624 _m1, MMP9: Mm00600163 _m1, TIMP-1: Mm01341361 _ml, TIMP-2: Mm00441825 _m1, Fibronectin: Mm01256744_m1, Type IV collagen: Mm01210125 _m1, MCP-1: Mm00441242 _m1, (Pro) renin receptor ((P)RR): Mm00510396_ml, and Glyceraldehyde 3-phosphate dehydrogenase (GAPDH): Mm99999915 _g1). Each measurement was repeated four times. The relative mRNA level in the sample was normalized for GAPDH content.

2.4. Immunohistochemical Staining of $M M P-2, M M P-9$, TIMP-1, TIMP-2, and F4/80. The mice were killed at 8 or 12 weeks of age. Immunohistochemistry was performed with cryostat kidney sections $(3 \mu \mathrm{m})$ as described previously [4]. Cryostat kidney sections ( $3 \mu \mathrm{m}$ ) were air-dried for $10 \mathrm{~min}$ and then fixed in cold acetone for $10 \mathrm{~min}$. Nonspecific staining was blocked by incubation with avidin for $20 \mathrm{~min}$ and then with biotin for $20 \mathrm{~min}$ using the avidin-biotin blocking kit (Vector Laboratories, Inc., Burlingame, CA, USA). Endogenous peroxidase activity was inhibited by incubation with methanol containing $3 \% \mathrm{H}_{2} \mathrm{O}_{2}$ for $10 \mathrm{~min}$. The sections were then incubated with primary antibodies (Abs) in $20 \%$ normal goat or rabbit serum in $2 \%$ bovine serum albumin at $4^{\circ} \mathrm{C}$ overnight. The primary antibodies (Abs) were as follows: goat polyclonal anti-MMP-2 Ab (R\&D Systems, Inc., Minneapolis, MN, USA), goat polyclonal anti-MMP-9 Ab (R\&D Systems, Inc.), rabbit polyclonal anti-TIMP-1 Ab (Abbiotec, LLC, San Diego, CA, USA), rabbit polyclonal anti-TIMP$2 \mathrm{Ab}$ (Abbiotec, LLC), and rat monoclonal anti-F4/80 Ab (MAC497GA; Serotec, Oxford, UK). The sections were incubated with secondary antibody. The secondary Abs were as follows: an anti-goat IgG (Dako, Carpinteria, CA, USA), antirabbit IgG (Vector Laboratories, Inc.), or anti-rat IgG (Cosmo Bio Co., Ltd, Tokyo, Japan). The sections were incubated with peroxidase-conjugated streptavidin antibodies (Dako), and 3,3-diaminobenzidine was then added for $5 \mathrm{~min}$ after which the slides were counterstained with hematoxylin. The staining 
TABLE 1: Biochemical profiles of KK mice and KK- $A^{y}$ mice.

\begin{tabular}{lccc}
\hline Mice & Untreated KK & Untreated KK- $A^{y}$ & Treated KK- $A^{y}$ \\
$n$ & 7 & & 10 \\
\hline 8 weeks of age & & $31.1 \pm 0.8$ & $31.3 \pm 1.6$ \\
$\quad$ Body weight (g) & $26.0 \pm 0.3^{*}$ & $104 \pm 2$ & $105 \pm 2$ \\
Systolic blood pressure (mmHg) & $103 \pm 4$ & $158 \pm 54$ & $150 \pm 78$ \\
Urinary albumin-creatinine ratio (mg/g.Cr) & $47 \pm 22^{*}$ & $110 \pm 6$ & $110 \pm 7$ \\
Fasting blood glucose (mg/dL) & $83 \pm 5^{*}$ & $4.3 \pm 0.3$ & $4.2 \pm 0.1$ \\
HbAlc (\%) & $4.0 \pm 0.2^{* *}$ & & $38.8 \pm 1.9$ \\
12 weeks of age & & $38.9 \pm 0.8$ & $96 \pm 2^{*}$ \\
Body weight (g) & $32.8 \pm 0.5^{*}$ & $116 \pm 28$ & $112 \pm 99^{*}$ \\
Systolic blood pressure (mmHg) & $116 \pm 5$ & $552 \pm 268$ & $108 \pm 7$ \\
Urinary albumin-creatinine ratio (mg/g.Cr) & $24 \pm 10^{*}$ & $105 \pm 10$ \\
Fasting blood glucose (mg/dL) & $106 \pm 5$ & $6.9 \pm 0.4$ & $6.7 \pm 0.2$ \\
HbAlc (\%) & $4.3 \pm 0.2^{*}$ & & \\
\hline
\end{tabular}

Data are expressed as means \pm SD.

${ }^{*} P<0.01$ (versus untreated KK- $A^{y}$ mice group), ${ }^{* *} P<0.05$ (versus untreated KK- $A^{y}$ mice group).

of at least 10 glomeruli from each mouse was quantified using the KS-400 version 4.0 image analysis system (KS400; Carl Zeiss Vision, Munich, Germany). The threshold was calculated as follows: the sum of the medium value of optical density in each group/the numbers of group. The number of F4/80-positive cells was counted in 10 randomly selected fields $(\times 200)$. Analyses were performed by two investigators in a blinded fashion $[4,20]$.

2.5. Western Blot Analysis of $p-p 38, p-E R K 1 / 2$, and $p$-SAPK/ JNK Expression. Portions of renal cortices samples were homogenized in lysis buffer containing a complete protease inhibitor cocktail tablet (Roche Diagnostics, Mannheim, Germany), $1 \mathrm{mM} \mathrm{NaF}$, and $1 \mathrm{mM}$ sodium orthovanadate (SigmaAldrich, Louis, MO, USA) and centrifuged. Appropriate volumes of the supernatant $(20 \mu \mathrm{g} / \mathrm{lane})$ were mixed with an equal volume of sample buffer $(312.5 \mathrm{mmol} / \mathrm{L}$ Tris- $\mathrm{HCl}$, $\mathrm{pH} 6.8,10 \%$ SDS, 50\% glycerol, 10\% 2-mercaptoethanol, and $0.025 \%$ bromophenol blue). SDS-PAGE gel electrophoresis and western blot analysis were performed according to standard protocols and were visualized using enhanced chemiluminescence immunoblot detection kits (ECL prime, Amersham Biosciences, Buckinghamshire, UK). The primary antibodies used were as follows: total p38, phosphorylated p38, total Erk1/2, phosphorylated Erk1/2, total SAPK-JNK, and phosphorylated SAPK-JNK (1:1000, Cell Signaling Technology, Inc., Danvers, MA, USA). HRPconjugated second antibodies (Jackson Immuno Research Laboratories, West Grove, PA, USA) were used in this study. The concentration was measured by a LAS-3000 image system (Fujifilm, Tokyo, Japan).

2.6. Measurement of NF- $\kappa B$ Activation. Nuclear extracts were obtained from renal cortices using a Nuclear Extract Kit (Active Motif, Tokyo, Japan) as described previously [5]. NF$\kappa \mathrm{B}$ activation was measured using an NF- $\kappa \mathrm{B}$ Transcription
Factor Assay Kit (Active Motif) according to the manufacturer's recommendations. NF- $\kappa \mathrm{B}$ activation was measured in triplicate using a spectrophotometer (Molecular Devices Spectra Max 340PC, Sunnyvale, CA, USA) at OD450.

2.7. Statistical Analysis. Data were expressed as the mean \pm SD. Statistical differences between means were determined using the Bonferroni $t$-test. A value of $P<0.05$ was considered statistically significant.

\section{Results}

3.1. Biochemical Parameters. There were no significant differences in the baseline values of BW, SBP, FBG, HbAlc, and ACR between the vehicle- and aliskiren-treated $\mathrm{KK}-A^{y}$ mice at 8 weeks of age. However, these parameters except SBP in the vehicle-treated KK- $A^{y}$ mice were much higher than those in the vehicle-treated KK mice (Table 1).

The results of the biochemical parameters of the mice at the end of the 4-week experimental protocol are shown in Table 1. BW, HbAlc levels, and ACRs in vehicle-treated KK$A^{y}$ mice were much higher than those in vehicle-treated KK mice. However, FBG levels and SBP did not differ among vehicle-treated KK mice and vehicle-treated KK- $A^{y}$ mice. SBP in aliskiren-treated KK- $A^{y}$ mice were significantly lower than those in the vehicle-treated KK- $A^{y}$ mice, throughout the treatment. The ACRs in aliskiren-treated KK- $A^{y}$ mice were significantly lower than those in the vehicle-treated KK- $A^{y}$ mice; however there was no statistically significant change in BW, FBG levels, and HbAlc levels between vehicle- and aliskiren-treated $\mathrm{KK}-A^{y}$ mice.

3.2. Real-Time PCR Analysis of MMP-2, MMP-9, TIMP1, TIMP-2, Fibronectin, Type IV Collagen, MCP-1, and (P)RR Expression in the Kidneys. MMP-2, MMP-9, TIMP-1, 


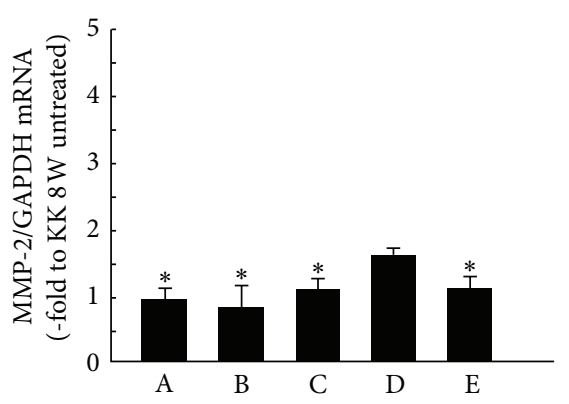

(a)

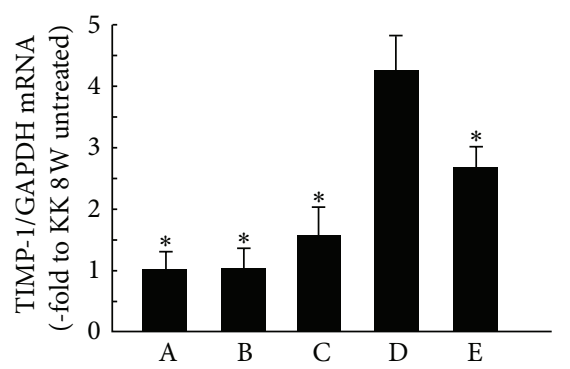

(c)

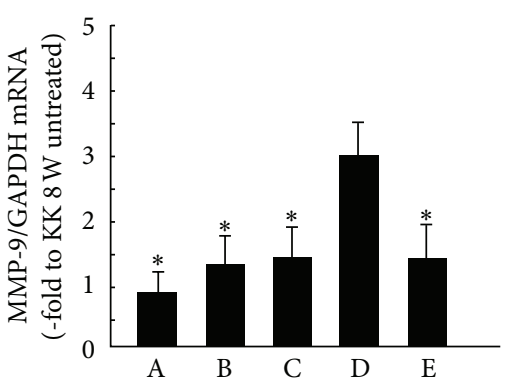

(b)

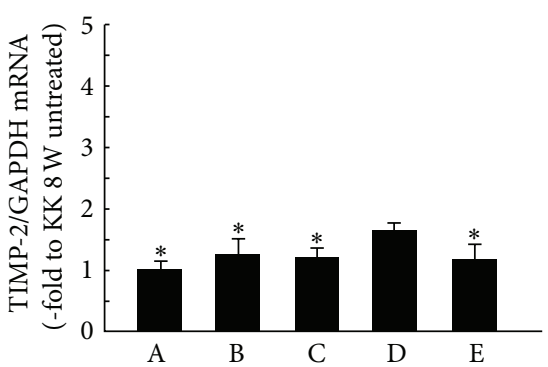

(d)

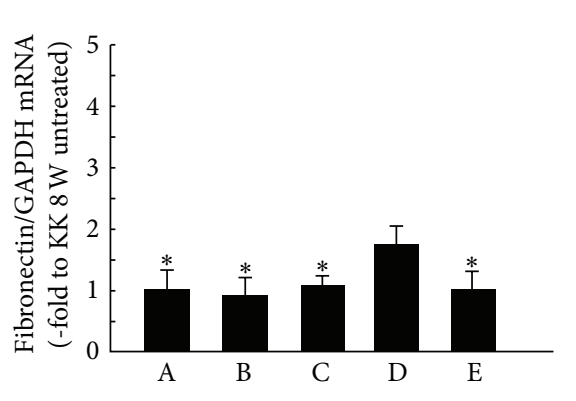

(e)

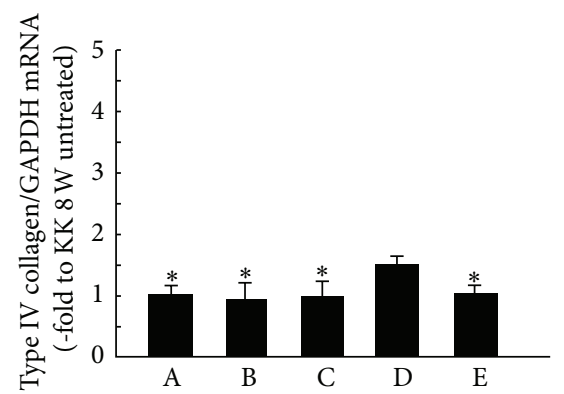

(f)

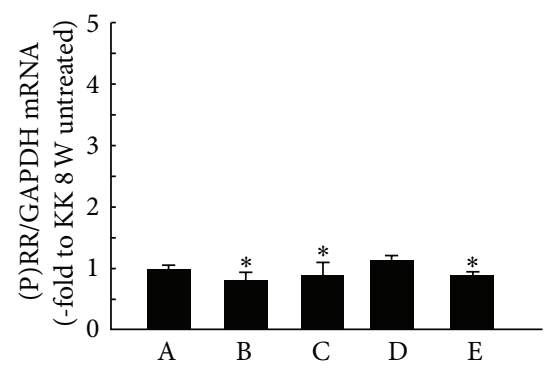

(h)

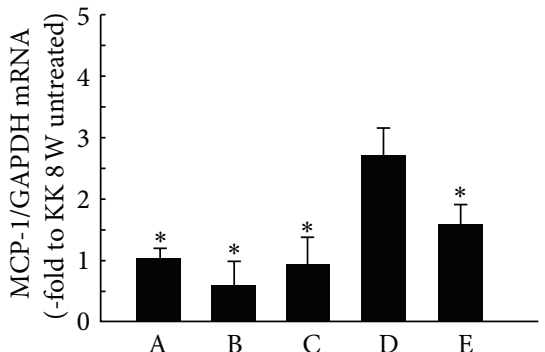

(g)

FIgURE 1: Expression of MMP-2, MMP-9, TIMP-1, TIMP-2, fibronectin, type IV collagen, MCP-1, and (P)RR in the kidneys of each mouse using real-time PCR (A: untreated KK mice at 8 weeks of age, B: untreated KK mice at 12 weeks of age, C: untreated KK- $A^{y}$ mice at 8 weeks of age, D: untreated KK- $A^{y}$ mice at 12 weeks of age, and E: treated KK- $A^{y}$ mice at 12 weeks of age). The ratio of MMP-2 (a), MMP-9 (b), TIMP-1 (c), TIMP-2 (d), fibronectin (e), type IV collagen (f), MCP-1 (g), and (P)RR (h) mRNAs to GAPDH mRNA is shown in the kidneys of mice from each group. These expressions were increased significantly in group 4 compared with groups 1,2 , and 3 . This increase was attenuated in group $5\left({ }^{*} P<0.001\right.$ versus untreated $\mathrm{KK}-A^{y}$ mice at 12 weeks of age).

TIMP-2, MCP-1, fibronectin, type IV collagen, MCP-1, and (P)RR mRNA expression in renal cortex tissues was increased significantly in group 4 compared with that in groups 1,2 , and $3(P<0.001$; Figures $1(\mathrm{a})-1(\mathrm{~h}))$. Aliskiren treatment (group 5 ) attenuated these increases in mRNA expression, resulting in an expression similar to that in the control KK mice (group 2) $(P<0.001$; Figures $1(\mathrm{a})-1(\mathrm{~h}))$.

3.3. Immunohistochemical Analysis of MMP-2, MMP-9, TIMP-1, TIMP-2, and F4/80 Expression in the Kidneys. 

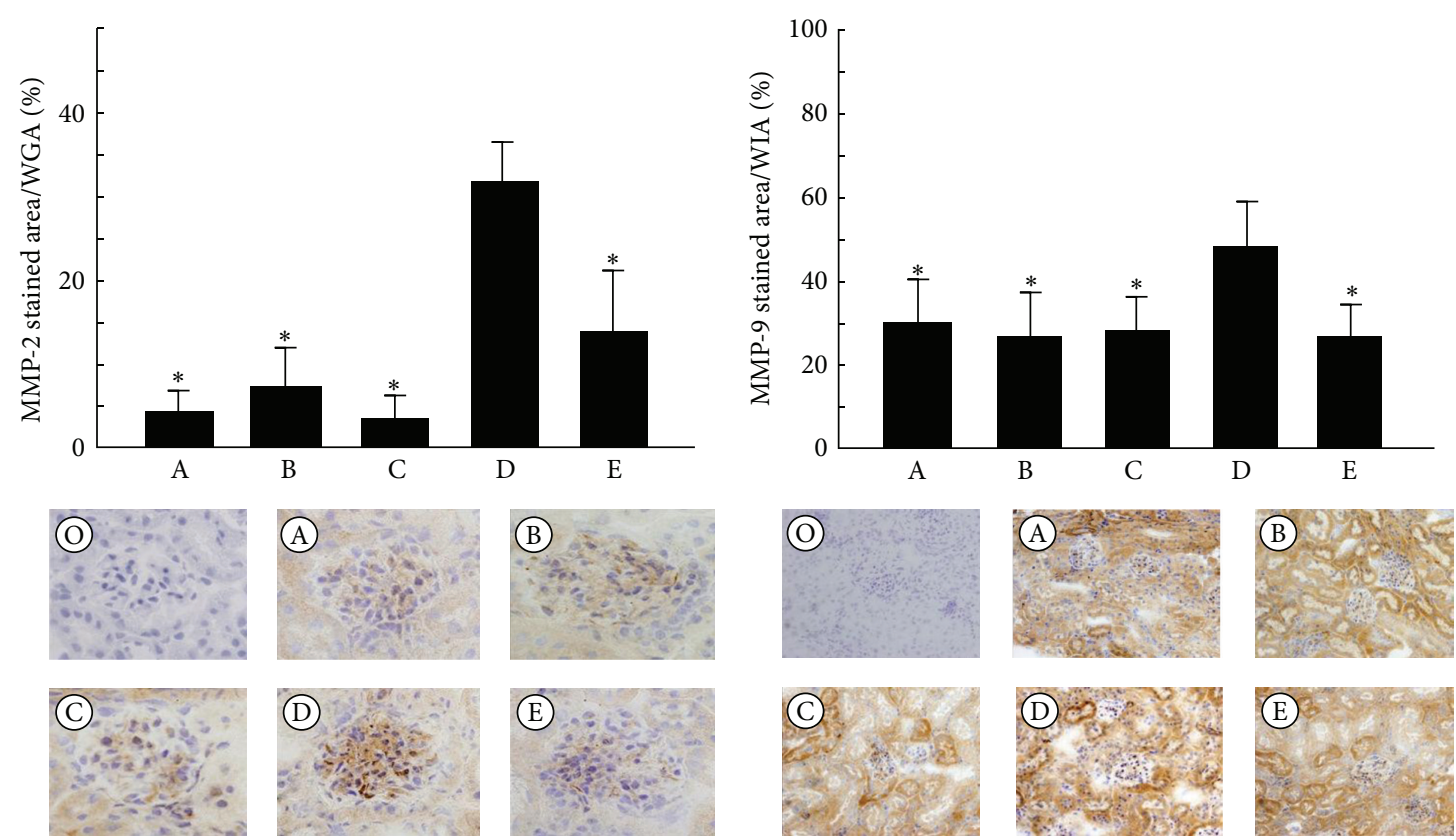

(a)

(b)
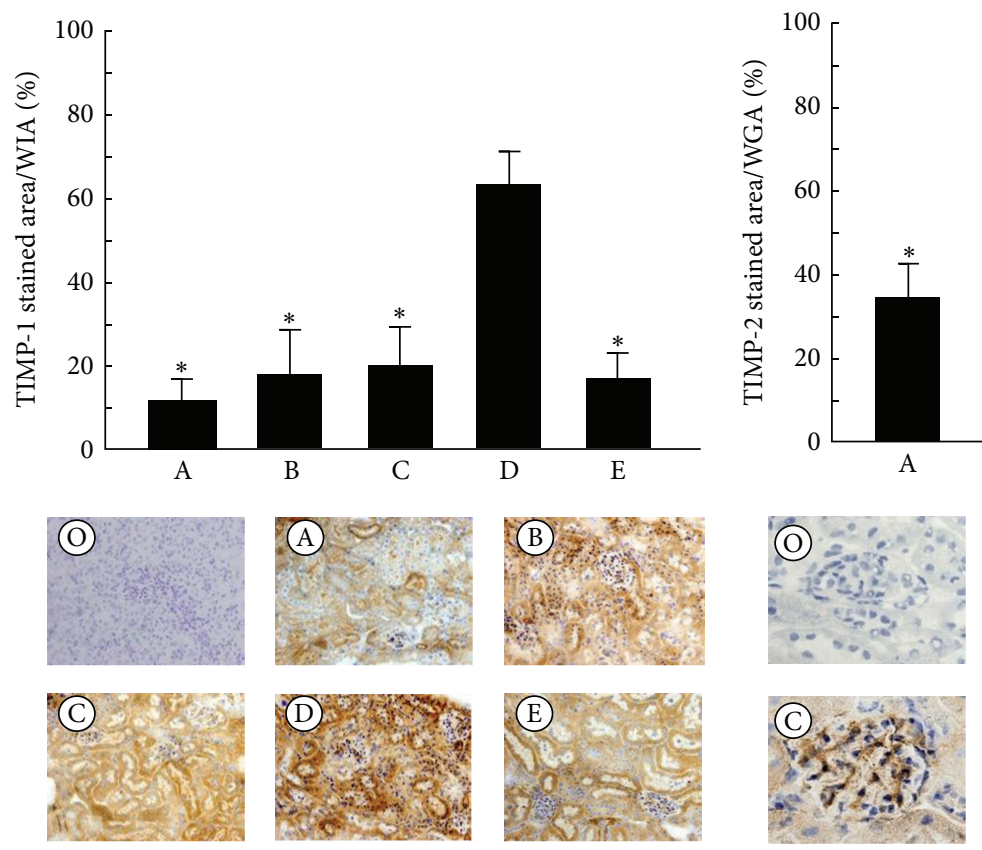

(c)
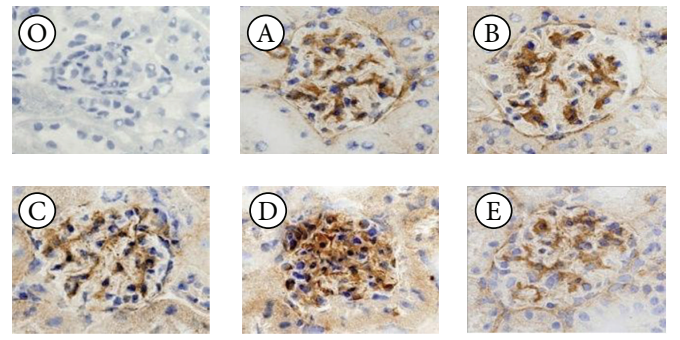

(d)

FIGURE 2: Immunohistochemical staining of MMP-2, MMP-9, TIMP-1, and TIMP-2 in the renal sections of each mouse (O: untreated KK- $A^{y}$ mice at 12 weeks of age without primary Ab, A: untreated KK mice at 8 weeks of age, B: untreated KK mice at 12 weeks of age, C: untreated KK$A^{y}$ mice at 8 weeks of age, D: untreated KK- $A^{y}$ mice at 12 weeks of age, and E: treated KK- $A^{y}$ mice at 12 weeks of age). Stainings showing the expression of MMP-2 (a), MMP-9 (b), TIMP-1 (c), and TIMP-2 (d) in the kidneys of mice from each group. These expressions were increased significantly in group 4 compared with groups 1,2 , and 3 . This increase was attenuated in group $5\left({ }^{*} P<0.001\right.$ versus untreated KK- $A^{y}$ mice at 12 weeks of age). Images were taken at 400-fold ( $\mathrm{a}$ and d) and 200-fold (b and c) magnification. WGA indicates whole glomerular area. WIA indicates whole interstitial area.

MMP-2 (Figure 2(a)) and TIMP-2 (Figure 2(d)) expression was observed in glomeruli, especially within the mesangial areas. MMP-9 (Figure 2(b)) and TIMP-1 (Figure 2(c)) expression was localized in the proximal tubules. MMP-2, MMP9, TIMP-1, and TIMP-2 protein accumulation was increased significantly in group 4 compared with that in groups 1,2 , and $3(P<0.001$; Figures $2(\mathrm{a})-2(\mathrm{~d}))$. Their expression was significantly suppressed in the aliskiren treatment groups $(P<0.001$; Figures 2(a)-2(d)). F4/80-positive cells were localized in the proximal tubules. The number of F4/80positive cells per $1000 \mu \mathrm{m}^{2}$ was significantly higher in group 4 than in groups 1,2 , and $3(P<0.001$; Figure 3$)$. These 
numbers were significantly lower in the aliskiren treatment groups $(P<0.001$; Figure 3$)$.

3.4. Western Blot Analysis of $p-p 38, p-E R K 1 / 2$, and $p$ $S A P K / J N K$ in the Kidneys. To examine the effect of aliskiren on MAPK activity in the kidneys of KK- $A^{y}$ mice, Western blot analysis was performed (Figures $4(\mathrm{a})-4(\mathrm{c})$ )). The protein expression of p-p38, p-ERK1/2, and p-SAPK/JNK in group 4 was significantly higher than that in groups 1,2 , and $3(P<$ 0.05 ; Figures $4(\mathrm{a})-4(\mathrm{c}))$. Their expressions were significantly suppressed in the aliskiren treatment groups $(P<0.05$; Figures 4(a)-4(c)).

3.5. Analysis of NF- $\kappa B$ Activation in the Kidneys. NF- $\kappa \mathrm{B}$ activity in group 4 was significantly higher than that in groups 1,2 , and 3 as shown in Figure $5(P<0.05$; Figure 5), and aliskiren suppressed this activation of NF- $\kappa \mathrm{B}(P<0.05$; Figure 5).

\section{Discussion}

The present study demonstrates for the first time that aliskiren dramatically ameliorated the levels of urinary ACR and renal fibrosis by improving inflammation and the alteration of MMPs and/or TIMPs expression in T2D KK- $A^{y}$ mice.

It is well known that the RAS pathway is activated in the diabetic kidney. Ang II increases the levels of MCP1 , which induces monocyte immigration and differentiation to macrophages and then augments ECM production and tubulointerstitial fibrosis [3, 21]. We have already demonstrated the presence of macrophage infiltration and increased MCP-1 expression in KK- $A^{y}$ mice [3, 4]. Recently, Tesch [22] reported that MCP-1 may have significant diagnostic value in evaluating the renal inflammatory response in DN. Moreover, Ang II induces the accumulation of type IV collagen and fibronectin through an imbalance within the MMPs/TIMPs system, which reduces the degradation of matrix proteins [16, 23]. However, the crosstalk between inflammation and the MMPs/TIMPs system remains controversial. In this study, we focused on MMP-2, MMP-9, TIMP-1, and TIMP-2 because these are the main regulators of the metabolism of type IV collagen, the most important ECM protein in DN, although MMP-2 also degrades fibronectin [24].

Data suggesting a link between MMPs/TIMPs dysregulation and DN also exist but are contradictory. Rodent models of diabetes revealed the decreased expression of MMP-2 [25$27]$ and MMP-9 $[28,29]$ in renal tissues. By contrast, the expression of the MMP inhibitors TIMP-1 $[30,31]$ and TIMP2 [16] was increased. In vitro, both decreases and increases in MMP-2 [32, 33] and MMP-9 $[32,34]$ secretion have been demonstrated when rodent mesangial and podocyte cells were cultured under high glucose conditions. In contrast, TIMP-1 [35] activity was increased in mesangial cells under high glucose conditions. In patients with $\mathrm{DN}$, both serum and urine MMP-2, MMP-9, and TIMP-1 concentrations increased with worsening glomerular lesions [36-39]. Several possible explanations can be offered to reconcile these differences: (1)

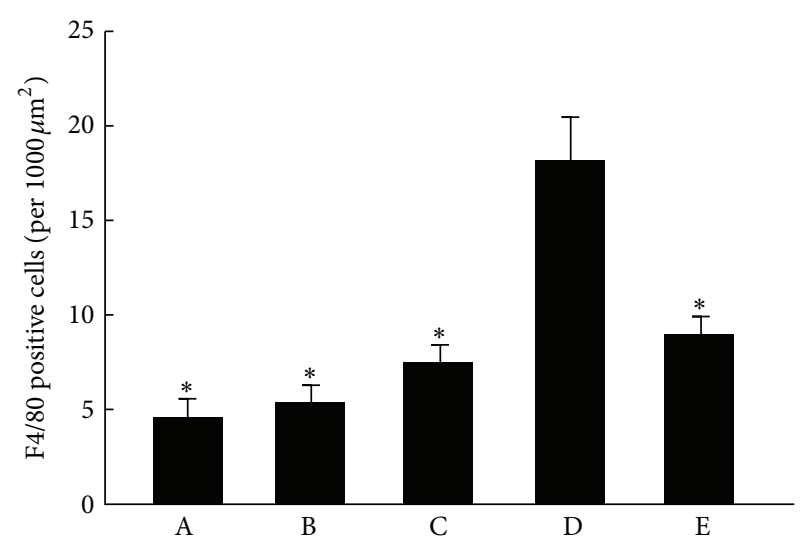

(a)
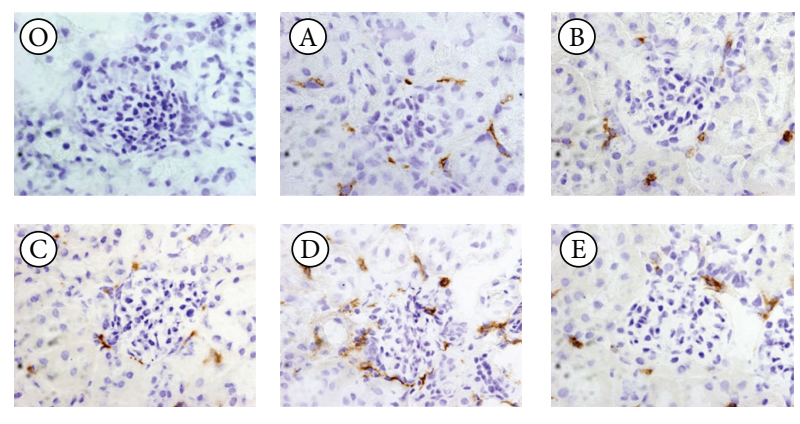

A: KK 8 W untreated (group 1)

B: KK $12 \mathrm{~W}$ untreated (group 2)

C: KK- $A^{y} 8 \mathrm{~W}$ untreated (group 3)

$\mathrm{D}: \mathrm{KK}-A^{y} 12 \mathrm{~W}$ untreated (group 4)

E: KK- $A^{y} 12 \mathrm{~W}$ treated (group 5)

${ }^{*} P<0.001$ versus (untreated KK- $A^{y} 12 \mathrm{~W}$ mice group)

(b)

FIGURE 3: Number of F4/80 positive cells and staining of the renal sections of each mouse (O: untreated KK- $A^{y}$ mice at 12 weeks of age without primary $\mathrm{Ab}, \mathrm{A}$ : untreated $\mathrm{KK}$ mice at 8 weeks of age, B: untreated KK mice at 12 weeks of age, C: untreated KK- $A^{y}$ mice at 8 weeks of age, D: untreated KK- $A^{y}$ mice at 12 weeks of age, and $\mathrm{E}$ : treated KK- $A^{y}$ mice at 12 weeks of age). The number of F4/80positive cells was counted to determine the macrophage infiltration in each group. Macrophage infiltration increased significantly in group 4 as compared with groups 1,2 , and 3 . This increase was attenuated in group $5\left({ }^{*} \mathrm{P}<0.001\right.$ versus untreated $\mathrm{KK}-A^{y}$ mice at 12 weeks of age). Images were taken at 200 -fold magnification.

differences in animal models, (2) differences in environment factors (i.e., in vitro and in vivo), and (3) differences in the stage of DN (early or late stage of kidney disease). The present study demonstrated for the first time that both the mRNA expression of MMP-2, MMP-9, TIMP-1, and TIMP-2, and the expression of those proteins clearly increased in the kidneys of T2D mice. Interestingly, MMP-2 and TIMP-2 expression was observed in the glomeruli, and their expression was more prominent in the mesangial areas than in the proximal tubules. MMP-2 and TIMP-2 may have been primarily related to glomerular basement membrane thickening and mesangial matrix expansion in this experiment. There is a possibility that at least some of the effects of MMP-9 and TIMP-1 could 


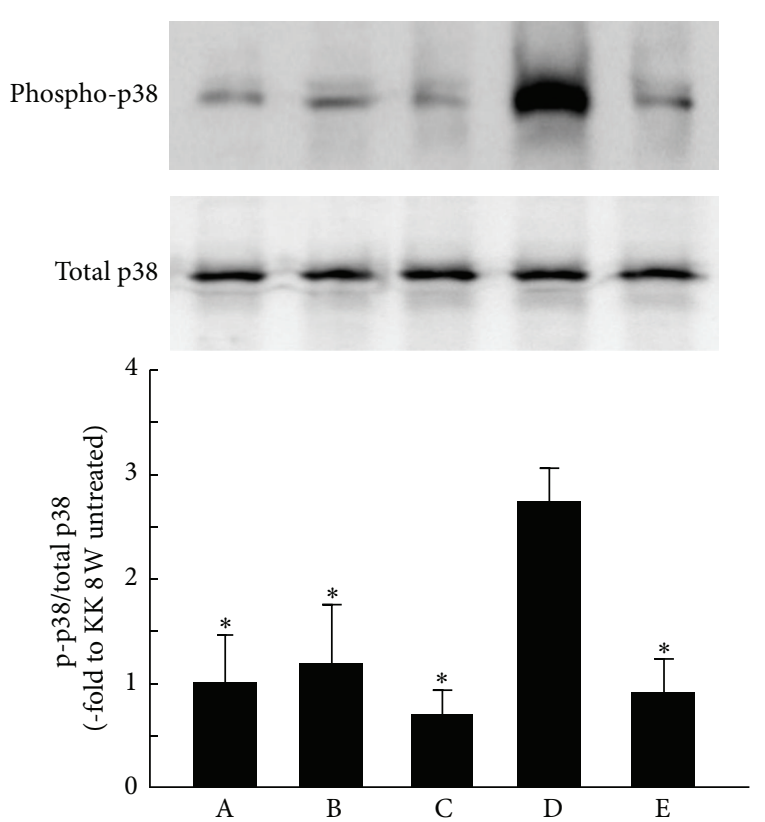

(a)

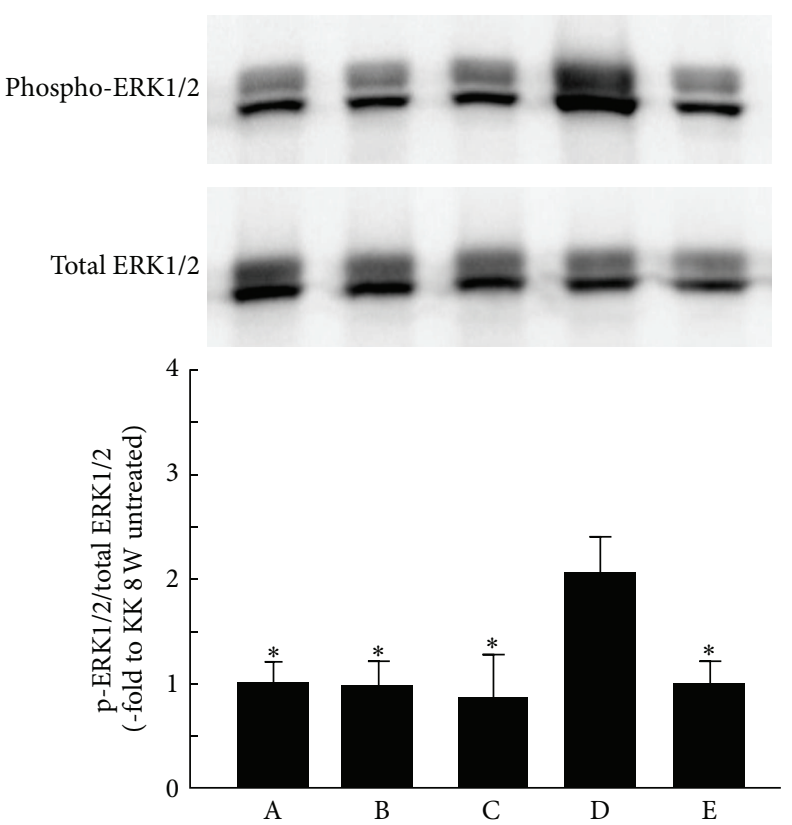

(b)

(a)

(b)
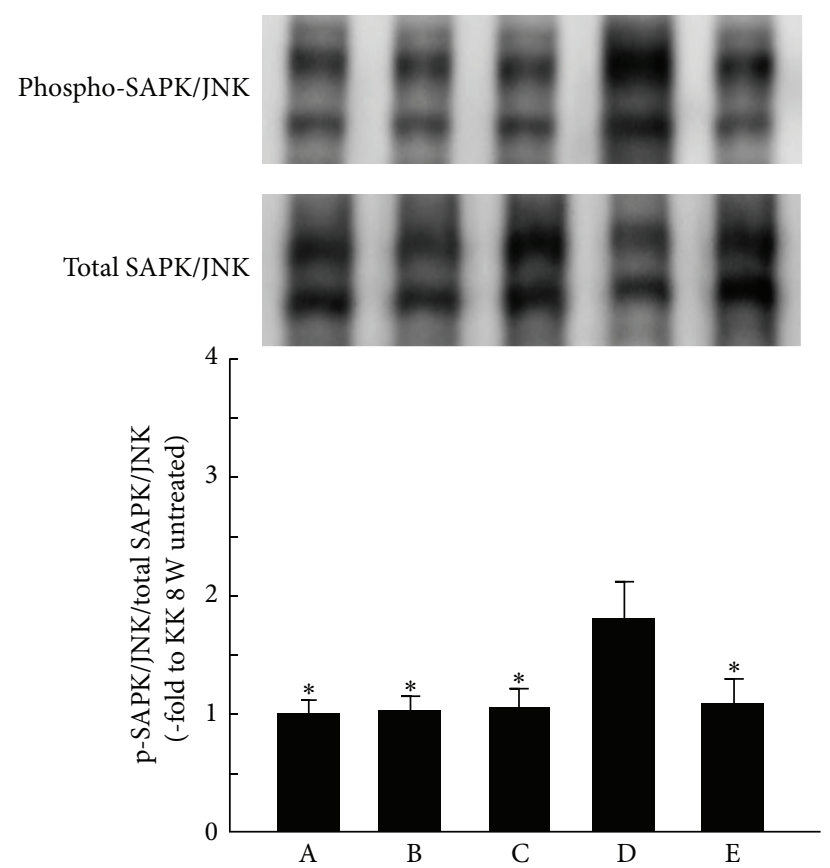

\begin{abstract}
A: KK $8 \mathrm{~W}$ untreated
B: KK $12 \mathrm{~W}$ untreated

C: KK- $A^{y} 8 \mathrm{~W}$ untreated

D: KK- $A^{y} 12 \mathrm{~W}$ untreated

E: KK- $A^{y} 12 \mathrm{~W}$ treated
\end{abstract}

${ }^{*} P<0.05$ versus (untreated KK- $A^{y} 12 \mathrm{~W}$ mice group)

(c)

(c)

FIGURE 4: Mean protein levels of p-p38, p-ERK1/2, and p-SAPK/JNK in each mouse using Western blot analysis (A: untreated KK mice at 8 weeks of age, B: untreated KK mice at 12 weeks of age, C: untreated KK- $A^{y}$ mice at 8 weeks of age, D: untreated KK- $A^{y}$ mice at 12 weeks of age, and E: treated KK- $A^{y}$ mice at 12 weeks of age). The expression of p-p38 (a), p-ERK1/2 (b), and p-SAPK/JNK (c) proteins is shown in the kidneys of mice from each group. These expressions were increased significantly in group 4 compared with groups 1,2 , and 3 . This increase was attenuated in group $5\left({ }^{*} \mathrm{P}<0.05\right.$ versus untreated KK- $A^{y}$ mice at 12 weeks of age $)$. 


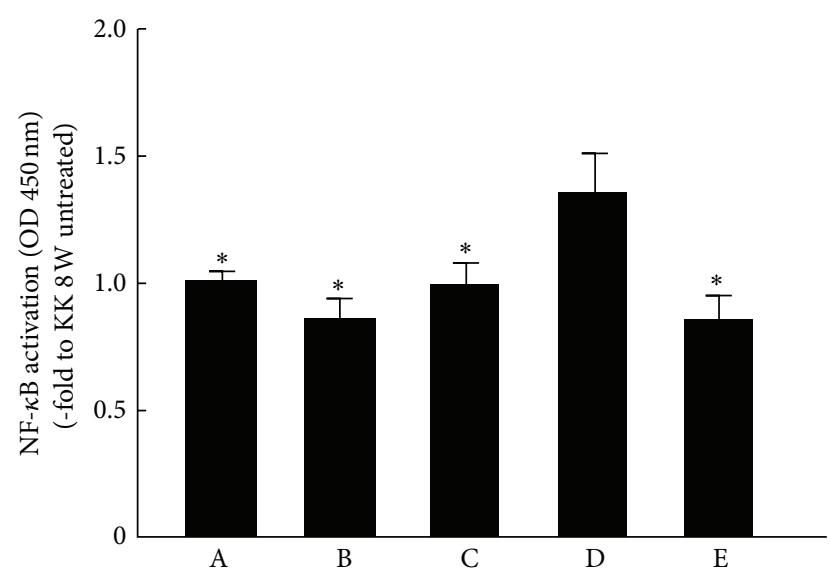

A: KK 8 W untreated

B: KK $12 \mathrm{~W}$ untreated

C: $\mathrm{KK}-A^{y} 8 \mathrm{~W}$ untreated

$\mathrm{D}: \mathrm{KK}-A^{y} 12 \mathrm{~W}$ untreated

E: KK- $A^{y} 12 \mathrm{~W}$ treated

${ }^{*} P<0.05$ versus (untreated $\mathrm{KK}-A^{y} 12 \mathrm{~W}$ mice group)

FIGURE 5: NF- $\kappa$ B activation in each mouse (A: untreated KK mice at 8 weeks of age, B: untreated KK mice at 12 weeks of age, C: untreated KK- $A^{y}$ mice at 8 weeks of age, D: untreated KK- $A^{y}$ mice at 12 weeks of age, and E: treated KK- $A^{y}$ mice at 12 weeks of age). The nuclear extracts were prepared and processed for the analysis of NF- $\kappa \mathrm{B}$ activation. The levels of NF- $\kappa \mathrm{B}$ activation were measured at OD450. These expressions were increased significantly in group 4 compared with groups 1,2 , and 3 . This increase was attenuated in group $5\left({ }^{*} P<0.05\right.$ versus untreated KK- $A^{y}$ mice at 12 weeks of age).

be mediated by MCP-1 system modulation, as macrophage infiltration was mainly observed in the proximal tubules. In contrast, the effects of MMP-2 and TIMP-2 might be related to Ang II and dependent on renin without dependence on inflammatory mediators such as MCP-1 and macrophages. Although we also sought to measure the mRNA or protein levels of IL-6 in glomeruli and urine, respectively, its levels were too subtle to be detected accurately. However, MCP1 was detectable in urine, and the levels of urinary MCP1 tended to be lower after aliskiren treatment, although significant differences were not observed (data not shown). Therefore, we consider that MCP-1 might be the most important marker of the progression of DN in this stage.

Ang II upregulation is known to modify the activity of tyrosine kinases and phosphatases, activate MAPK, and stimulate transcriptional factors [40, 41]. In addition, renin induces direct $(\mathrm{P}) \mathrm{RR}$ signaling, leading to MAPK activation that is independent of Ang II [42-44]. Feldt et al. [45] reported that plasma renin activity can be blocked by aliskiren administration; however, the direct $(\mathrm{P}) \mathrm{RR}$ signaling resulting in MAPK activation and $(\mathrm{P}) \mathrm{RR}$ gene expression cannot be inhibited by aliskiren. In contrast, Feldman et al. [46] indicated that aliskiren inhibits (P)RR gene expression in vivo. Thus, we sought to determine whether aliskiren can alter $(\mathrm{P}) \mathrm{RR}$ gene expression in our mouse model. These beneficial effects of aliskiren might be related to the suppression of renal MAPK activity, which may be Ang II- and/or
(P)RR-dependent. We speculate that in addition to lowering systemic BP and blocking the circulating and tissue RAS system, aliskiren may have an antifibrotic action that may be mediated by $(\mathrm{P}) \mathrm{RR}$ as follows: suppression of $(\mathrm{P}) \mathrm{RR}$ gene expression may decrease the numbers of receptors, dampen intracellular fibrotic pathways induced by (pro) renin, and negate the gain in activity of receptor-bound renin. Because our data could not indicate whether aliskiren inhibits Ang II or (P)RR pathways, more work will be needed to clarify this issue.

Several possible explanations can be offered to reconcile these differences of the results between the ALTITUDE study and the present study. (1) It is certainly difficult to compare simply the results of human model with those of mouse model. In our mouse model, the levels of serum creatinine did not increase, although the levels of urinary ACR were relatively high [4]. (2) Adverse events of hyperkalemia and hypotension which were observed in aliskiren monotherapy such as our study were probably much lower than those in combination therapy of aliskiren added to standard-ofcare renin-angiotensin blockade such as ALTITUDE study. Therefore, we consider that there is the possible benefits of aliskiren monotherapy in early stage of diabetic patients. However, we need further study under various conditions to determine the possible benefits of aliskiren, because unlike the ALITITUDE study, the end point of our study was not end-stage renal disease or cardiovascular death.

The main limitations of our study are as follows. The treatment protocol used in this study affected blood pressure. Thus, the beneficial effects of aliskiren might be partly derived from antihypertensive effects. Furthermore, we did not demonstrate the natural course of renal MMPs/TIMPs, type IV collagen, fibronectin, and MCP-1 expression until the late stages of DN. However, the objective of this study was to determine the changes in cytokine and MMPs/TIMPs levels in response to high glucose or Ang II and to observe aliskireninduced changes in their levels during the early stages of DN.

In conclusion, it appears that aliskiren reduces albuminuria and inhibits the renal fibrosis in diabetic kidney disease. These effects might be related to the regulation of the alteration between collagen synthesis and degradation and to inflammation via the activation of MAPK and NF- $\kappa$ B via Ang II- and/or (P)RR-mediated actions.

\section{Conflict of Interests}

The authors declare no conflict of interests.

\section{Authors' Contribution}

All authors contributed to the conception and design, or analysis and interpretation of data, drafting the paper or revised it critically, and approved the final version of the paper for publication. Masako Furukawa and Tomohito Gohda contributed to the experimental work. Masako Furukawa, Tomohito Gohda and Yasuhiko Tomino drafted the paper and revised it most critically. 


\section{Acknowledgments}

The authors thank Novartis Pharmaceutical Corporation for providing aliskiren. They also thank R. Mineki, Ph.D., Y. Kojima, Ph.D., N. Sueyoshi, T. Ikegami, Ph.D., T. Ikeda, and T. Shibata for their skillful technical support.

\section{References}

[1] A. Mathew, R. Cunard, and K. Sharma, "Antifibrotic treatment and other new strategies for improving renal outcomes," Contributions to Nephrology, vol. 170, pp. 217-227, 2011.

[2] D. Choudhury, M. Tuncel, and M. Levi, "Diabetic nephropathy-a multifaceted target of new therapies," Discovery Medicine, vol. 10, no. 54, pp. 406-415, 2010.

[3] S. Hagiwara, Y. Makita, L. Gu et al., "Eicosapentaenoic acid ameliorates diabetic nephropathy of type 2 diabetic KKAy/Ta mice: involvement of MCP-1 suppression and decreased ERK1/2 and p38 phosphorylation," Nephrology Dialysis Transplantation, vol. 21, no. 3, pp. 605-615, 2006.

[4] I. Ohara, M. Tanimoto, T. Gohda et al., "Effect of combination therapy with angiotensin receptor blocker and 1,25dihydroxyvitamin D3 in type 2 diabetic nephropathy in KK$A^{y} /$ Ta mice," Nephron, vol. 117, no. 4, pp. e124-e132, 2011.

[5] J. Y. Moon, M. Tanimoto, T. Gohda et al., "Attenuating effect of angiotensin-(1-7) on angiotensin II-mediated $\mathrm{NAD}(\mathrm{P}) \mathrm{H}$ oxidase activation in type 2 diabetic nephropathy of $\mathrm{KK}-A^{y} / \mathrm{Ta}$ mice," American Journal of Physiology, vol. 300, no. 6, pp. F1271F1282, 2011.

[6] T. Ito, M. Tanimoto, K. Yamada et al., "Glomerular changes in the KK- $A^{y} /$ Ta mouse: a possible model for human type 2 diabetic nephropathy," Nephrology, vol.11, no. 1, pp. 29-35, 2006.

[7] U. C. Brewster and M. A. Perazella, "The renin-angiotensinaldosterone system and the kidney: effects on kidney disease," American Journal of Medicine, vol. 116, no. 4, pp. 263-272, 2004.

[8] F. C. Luft, "Proinflammatory effects of angiotensin II and endothelin: targets for progression of cardiovascular and renal diseases," Current Opinion in Nephrology and Hypertension, vol. 11, no. 1, pp. 59-66, 2002.

[9] G. Wolf, "Angiotensin II as a mediator of tubulointerstitial injury," Nephrology Dialysis Transplantation, vol. 15, supplement 6, pp. 61-63, 2000.

[10] M. J. Brown, “Aliskiren," Circulation, vol. 118, no. 7, pp. 773-784, 2008.

[11] C. Jensen, P. Herold, and H. R. Brunner, "Aliskiren: the first renin inhibitor for clinical treatment," Nature Reviews Drug Discovery, vol. 7, no. 5, pp. 399-410, 2008.

[12] E. Yamamoto, K. Kataoka, Y. F. Dong et al., "Aliskiren enhances the protective effects of valsartan against cardiovascular and renal injury in endothelial nitric oxide synthase-deficient mice," Hypertension, vol. 54, no. 3, pp. 633-638, 2009.

[13] D. M. Riche, D. S. Minor, A. S. Holdiness, and H. E. East, "An issue of dependence: implications from the Aliskiren in the evaluation of proteinuria in diabetes (AVOID) trial," Journal of Clinical Hypertension, vol. 11, no. 2, pp. 89-93, 2009.

[14] H. H. Parving, B. M. Brenner, J. J. McMurray et al., "Baseline characteristics in the aliskiren trial in type 2 diabetes using cardio-renal endpoints (ALTITUDE)," Journal of the ReninAngiotensin-Aldosterone System, vol. 13, no. 3, pp. 387-393, 2012.

[15] C. Van Kooten, A. M. J. Langers, J. A. Bruijn, and M. R. Daha, "Role of tubular cells in progressive renal disease," Kidney and Blood Pressure Research, vol. 22, no. 1-2, pp. 53-61, 1999.
[16] S. Y. Han, Y. H. Jee, K. H. Han et al., "An imbalance between matrix metalloproteinase-2 and tissue inhibitor of matrix metalloproteinase- 2 contributes to the development of early diabetic nephropathy," Nephrology Dialysis Transplantation, vol. 21, no. 9, pp. 2406-2416, 2006.

[17] P. Ronco and C. Chatziantoniou, "Matrix metalloproteinases and matrix receptors in progression and reversal of kidney disease: therapeutic perspectives," Kidney International, vol. 74, no. 7, pp. 873-878, 2008.

[18] M. Iwai, H. Kanno, Y. Tomono et al., "Direct renin inhibition improved insulin resistance and adipose tissue dysfunction in type 2 diabetic KK- $A^{y}$ mice," Journal of Hypertension, vol. 28, no. 7, pp. 1471-1481, 2010.

[19] R. M. Fryer, P. A. Rakestraw, M. Nakane et al., "Differential inhibition of renin mRNA expression by paricalcitol and calcitriol in C57/BL6 mice," Nephron, vol. 106, no. 4, pp. p76-p81, 2007.

[20] Q. Fan, J. Liao, M. Kobayashi et al., "Candesartan reduced advanced glycation end-products accumulation and diminished nitro-oxidative stress in type 2 diabetic KK/Ta mice," Nephrology Dialysis Transplantation, vol. 19, no. 12, pp. 30123020, 2004.

[21] Y. Ozawa, H. Kobori, Y. Suzaki, and L. G. Navar, "Sustained renal interstitial macrophage infiltration following chronic angiotensin II infusions," American Journal of Physiology, vol. 292, no. 1, pp. F330-F339, 2007.

[22] G. H. Tesch, "MCP-1/CCL2: a new diagnostic marker and therapeutic target for progressive renal injury in diabetic nephropathy," American Journal of Physiology, vol. 294, no. 4, pp. F697-F701, 2008.

[23] A. O. Phillips, R. Steadman, K. Morrisey, J. Martin, L. Eynstone, and J. D. Williams, "Exposure of human renal proximal tubular cells to glucose leads to accumulation of type IV collagen and fibronectin by decreased degradation," Kidney International, vol. 52, no. 4, pp. 973-984, 1997.

[24] P. Ronco, B. Lelongt, R. Piedagnel, and C. Chatziantoniou, "Matrix metalloproteinases in kidney disease progression and repair: a case of flipping the coin," Seminars in Nephrology, vol. 27, no. 3, pp. 352-362, 2007.

[25] S. X. Zhang, J. J. Wang, K. Lu, R. Mott, R. Longeras, and J. X. Ma, "Therapeutic potential of angiostatin in diabetic nephropathy," Journal of the American Society of Nephrology, vol. 17, no. 2, pp. 475-486, 2006.

[26] A. Inada, K. Nagai, H. Arai et al., "Establishment of a diabetic mouse model with progressive diabetic nephropathy," American Journal of Pathology, vol. 167, no. 2, pp. 327-336, 2005.

[27] S. Z. Sun, Y. Wang, Q. Li, Y. J. Tian, M. H. Liu, and Y. $\mathrm{H}$. Yu, "Effects of benazepril on renal function and kidney expression of matrix metalloproteinase- 2 and tissue inhibitor of metalloproteinase-2 in diabetic rats," Chinese Medical Journal, vol. 119, no. 10, pp. 814-821, 2006.

[28] S. V. McLennan, D. J. Kelly, A. J. Cox et al., "Decreased matrix degradation in diabetic nephropathy: effects of ACE inhibition on the expression and activities of matrix metalloproteinases," Diabetologia, vol. 45, no. 2, pp. 268-275, 2002.

[29] A. Dixon and C. Maric, "17 $\beta$-Estradiol attenuates diabetic kidney disease by regulating extracellular matrix and transforming growth factor- $\beta$ protein expression and signaling," American Journal of Physiology, vol. 293, no. 5, pp. F1678-F1690, 2007.

[30] A. A. Eddy, "Molecular insights into renal interstitial fibrosis," Journal of the American Society of Nephrology, vol. 7, no. 12, pp. 2495-2508, 1996. 
[31] S. E. Thomson, S. V. McLennan, P. D. Kirwan et al., "Renal connective tissue growth factor correlates with glomerular basement membrane thickness and prospective albuminuria in a non-human primate model of diabetes: possible predictive marker for incipient diabetic nephropathy," Journal of Diabetes and its Complications, vol. 22, no. 4, pp. 284-294, 2008.

[32] A. Fornoni, L. J. Striker, F. Zheng, and G. E. Striker, "Reversibility of glucose-induced changes in mesangial cell extracellular matrix depends on the genetic background," Diabetes, vol. 51, no. 2, pp. 499-505, 2002.

[33] R. Singh, R. H. Song, N. Alavi, A. A. Pegoraro, A. K. Singh, and D. J. Leehey, "High glucose decreases matrix metalloproteinase2 activity in rat mesangial cells via transforming growth factorB1," Experimental Nephrology, vol. 9, no. 4, pp. 249-257, 2001.

[34] Y. Bai, L. Wang, Y. Li et al., "High ambient glucose levels modulates the production of MMP-9 and $\alpha 5$ (IV) collagen by cultured podocytes," Cellular Physiology and Biochemistry, vol. 17, no. 1-2, pp. 57-68, 2006.

[35] E. Lupia, S. J. Elliot, O. Lenz et al., "IGF-1 decreases collagen degradation in diabetic NOD mesangial cells: implications for diabetic nephropathy," Diabetes, vol. 48, no. 8, pp. 1638-1644, 1999.

[36] M. Diamantt, R. Hanemaaijer, J. H. Verheijen, J. W. A. Smit, J. K. Radder, and H. H. P. J. Lemkes, "Elevated matrix metalloproteinase- 2 and -9 in urine, but not in serum, are markers of type 1 diabetic nephropathy," Diabetic Medicine, vol. 18 , no. 5, pp. 423-424, 2001.

[37] K. Tashiro, I. Koyanagi, I. Ohara et al., "Levels of urinary matrix metalloproteinase-9 (MMP-9) and renal injuries in patients with type 2 diabetic nephropathy," Journal of Clinical Laboratory Analysis, vol. 18, no. 3, pp. 206-210, 2004.

[38] A. Lauhio, T. Sorsa, R. Srinivas et al., "Urinary matrix metalloproteinase $-8,-9,-14$ and their regulators (TRY-1, TRY-2, TATI) in patients with diabetic nephropathy," Annals of Medicine, vol. 40, no. 4, pp. 312-320, 2008.

[39] M. Kanauchi, H. Nishioka, Y. Nakashima, T. Hashimoto, and K. Dohi, "Role of tissue inhibitors of metalloproteinase in diabetic nephropathy," Japanese Journal of Nephrology, vol. 38, no. 3, pp. 124-128, 1996.

[40] M. Dharmani, M. R. Mustafa, F. I. Achike, and M. K. Sim, "Effects of angiotensin 1-7 on the actions of angiotensin II in the renal and mesenteric vasculature of hypertensive and streptozotocin-induced diabetic rats," European Journal of Pharmacology, vol. 561, no. 1-3, pp. 144-150, 2007.

[41] E. Ritz and V. Haxsen, "Angiotensin II and oxidative stress: an unholy alliance," Journal of the American Society of Nephrology, vol. 14, no. 11, pp. 2985-2987, 2003.

[42] G. Nguyen, F. Delarue, C. Burcklé, L. Bouzhir, T. Giller, and J. D. Sraer, "Pivotal role of the renin/prorenin receptor in angiotensin II production and cellular responses to renin," Journal of Clinical Investigation, vol. 109, no. 11, pp. 1417-1427, 2002.

[43] Y. Huang, N. A. Noble, J. Zhang, C. Xu, and W. A. Border, "Renin-stimulated TGF- $\beta 1$ expression is regulated by a mitogen-activated protein kinase in mesangial cells," Kidney International, vol. 72, no. 1, pp. 45-52, 2007.

[44] Y. Huang, S. Wongamorntham, J. Kasting et al., "Renin increases mesangial cell transforming growth factor- $\beta 1$ and matrix proteins through receptor-mediated, angiotensin II-independent mechanisms," Kidney International, vol. 69, no. 1, pp. 105-113, 2006.

[45] S. Feldt, U. Maschke, R. Dechend, F. C. Luft, and D. N. Muller, "The putative (pro)renin receptor blocker HRP fails to prevent (pro)renin signaling," Journal of the American Society of Nephrology, vol. 19, no. 4, pp. 743-748, 2008.

[46] D. L. Feldman, L. Jin, H. Xuan et al., "Effects of aliskiren on blood pressure, albuminuria, and (pro)renin receptor expression in diabetic TG(mRen-2)27 Rats," Hypertension, vol. 52, no. 1, pp. 130-136, 2008. 


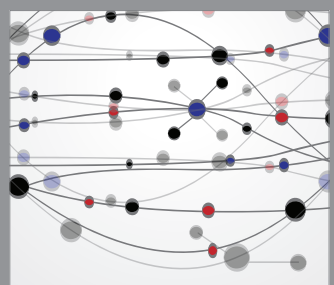

The Scientific World Journal
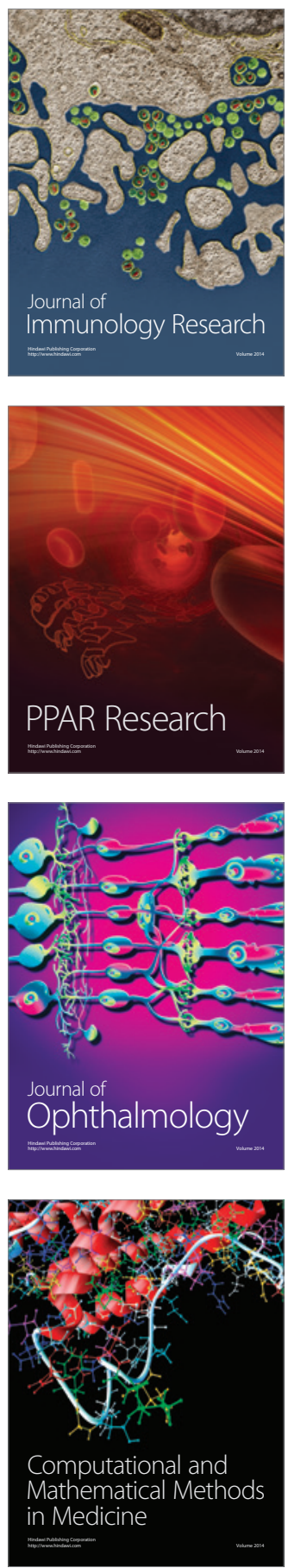

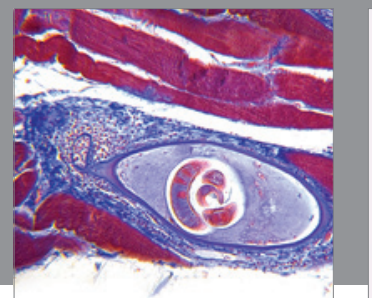

Gastroenterology

Research and Practice
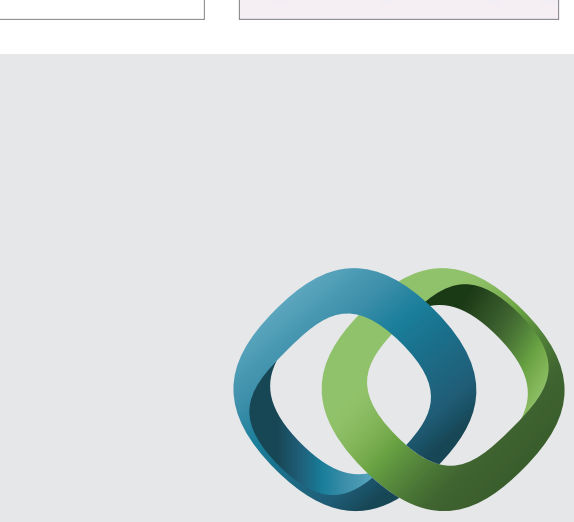

\section{Hindawi}

Submit your manuscripts at

http://www.hindawi.com
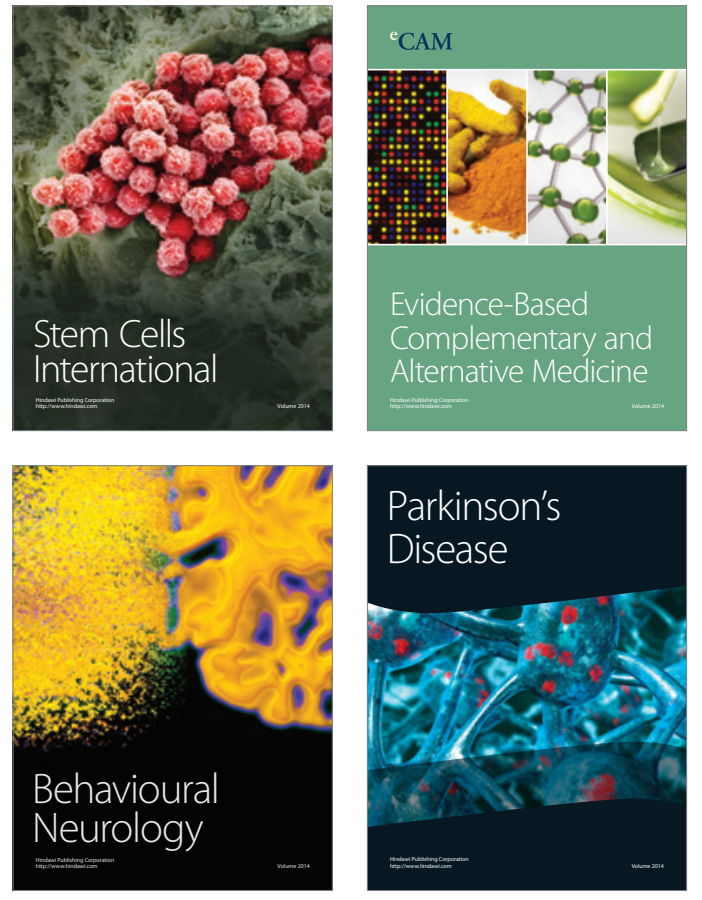
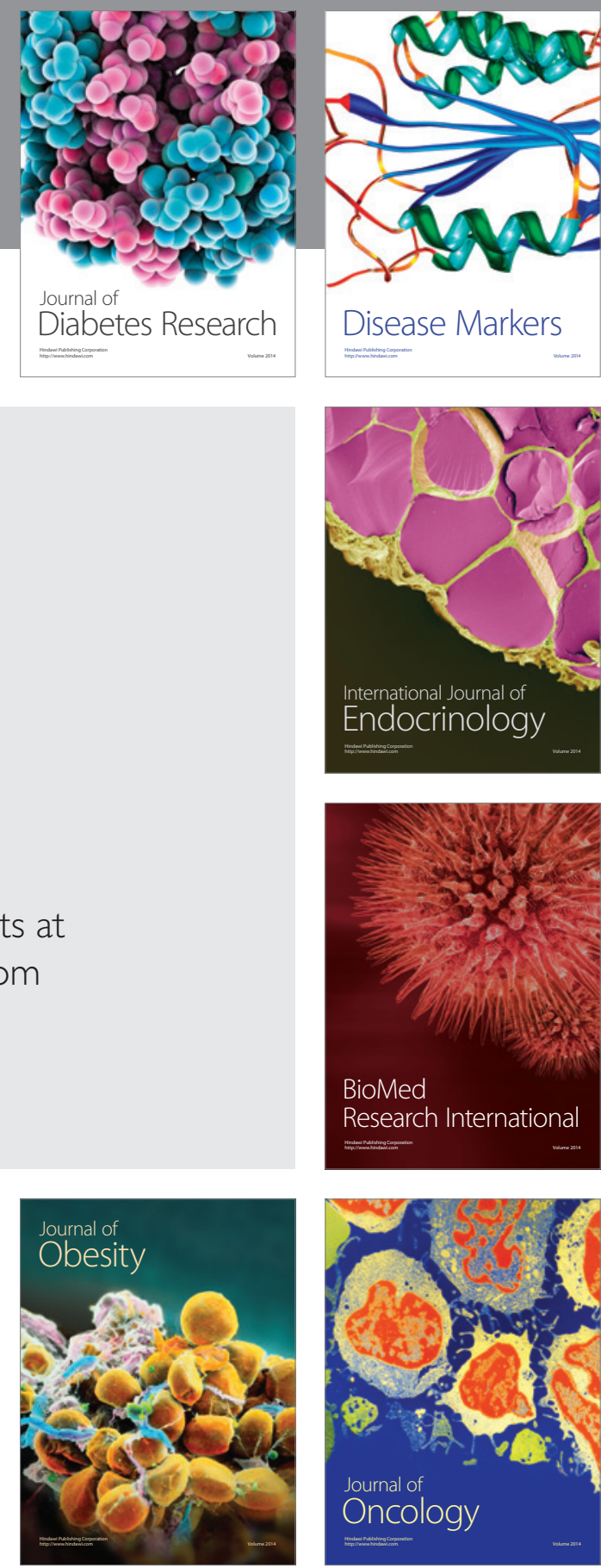

Disease Markers
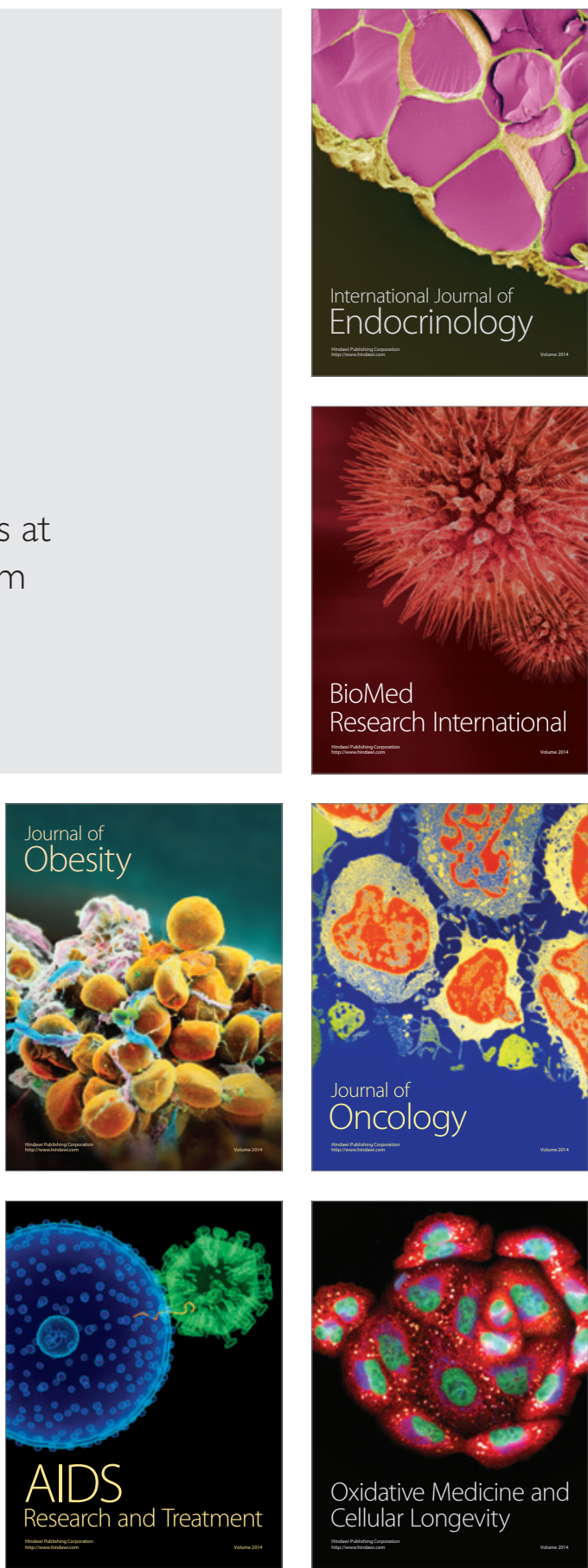